\title{
Contributions of participatory ergonomics to the improvement of safety culture in an industrial context
}

\author{
Carine Lallemand \\ Service Sciences and Innovation Department, Public Research Centre Henri Tudor, 29 avenue John F. Kennedy, \\ L-1855 Luxembourg, Luxembourg.Tel: (+352) 42.59.91-1. E-mail: carine.lallemand@tudor.lu
}

\begin{abstract}
This paper presents the results of an ergonomic intervention conducted within a blast furnace plant. As part of its risk prevention program, the company decided to set up an action plan, in a participatory manner, by setting up working groups to solve health \& safety issues. This field mission involved 230 employees, 80 of whom participated actively by being incorporated into working groups. After four months of intervention, a questionnaire survey has been conducted among employees to study the effects of participation on the safety climate. The results seem promising and show that the benefits of participation are numerous: a more positive safety climate associated to safer attitudes and behaviors. However, rather than just participation, it seems to be the employee involvement in the working groups and the satisfaction they derive from their participation that guarantee these positive results. Hence, participatory ergonomics seems to be an effective way to decrease the number of unsafe behaviors at work, provided that the type of participation has been previously well defined and organized according to the specific context of each organization.
\end{abstract}

Keywords: health \& safety, participatory ergonomics, safety culture, safety climate, industrial context

\section{Introduction}

In the last few years, the issue of health \& safety at work attracted the interest of both the research community and practitioners, especially in industrial contexts where workplace hazards are numerous.

Prior research has shown that, besides technical factors, employees' unsafe actions may be the primary cause of workplace accidents $[15,17,28]$. It makes sense, therefore, that industrial companies are trying to understand and modify these behaviors.

To address this problem, the development of a positive safety culture appears as a key organizational factor in order to develop safer behaviors amongst employees [2]. As a reflection of safety culture [4], the concept of safety climate has been the focus of many research studies $[31,19]$. Their main goals were to determine how to measure this climate and to understand which factors could improve it. Employees' participation in actions to improve their own safety was found out to be one of these factors [23]. Thus, as participation is a framework and a foundation for ergonomics [29], this work aims at studying the contributions of participatory ergonomics to the improvement of safety culture in an industrial context.

\subsection{Safety culture}

1.1.1. Safety culture as part of organizational culture Safety culture may be understood as the attitudes, beliefs, perceptions and values that employees share in relation to safety [3]. Safety culture may thus be considered as a part of organizational culture, in a framework that is limited or related to safety [22].

Within the organization, the safety culture may be dependent on many factors that demonstrate the organizational commitment for safety, as for example management decisions, organizational policies but also safety-related practices and processes [11].

\subsubsection{An important issue for prevention}

A positive safety culture may be described as a culture that reflects a shared understanding by employees that safety is the first priority in the company 
[14]. It seems that an organization that develops and maintains a strong safety culture will be more effective at preventing accidents, particularly through the impact of safety culture on attitudes and behaviors of employees [2].

At a psychosocial level, it is interesting to note that the safety culture may predict different positive attitudes at work. A positive safety culture would be likely be, for instance, to increase job satisfaction, work involvement or organizational commitment [20].

Interest in safety culture is therefore also justified by the broader impacts incurred, beyond the scope of safety and ensuring the organization benefits in terms of job performance of employees [9]. Thus, it is not surprising that this concept has attracted the attention of industry and researchers who have developed numerous models and tools to understand and measure the safety culture.

\subsubsection{Safety climate: a measure of safety culture}

Review of the literature shows that the more significant indicator of safety culture within a company is the safety climate [4]. Mearns, Whitaker \& Flin [19] describe it as the manifestation of safety culture in the behavior and attitudes expressed by employees.

Safety climate can be considered as an alternative indicator of the safety performance of an organization. It makes it possible to overcome the limitations of traditional measures such as the frequency rate of accidents and their analysis. First, these are not sensitive enough to provide useful information in the short to medium term and learn about the impacts of a participatory intervention [10]. Second, these performance measures simply provide factual information that shed no light on the perceptions of employees on safety.

This information, which is given by the measure of safety climate, may have an important preventive purpose [17]. As proof, safety climate is described by Flin, Mearns, O'Connor \& Bryden [7] as a major indicator of safety performance because it is associated with both safety practices [31,26], occupational accidents [19] and safe behaviors at work [1]. Many authors emphasize as well the fact that organizations can no longer be content to collect information on workplace accidents, but they must develop proactive approaches, whose the study of the security environment is part of [9].

Many scales for measuring the safety climate have been developed in recent years [32,1,22,11]. Furthermore, to understand how the safety climate im- pacts safe behaviors at work, some authors have developed structural models that explain such behavior [1,23]. Seo's model [23] establishes linkages between safety climate, workload, risk perception, perceived barriers and unsafe behaviors. It shows that among these factors, the perceived safety climate is the best predictor of unsafe behaviors.

\subsection{Participatory ergonomics and risk prevention}

\subsubsection{Participatory ergonomics}

If the practice of ergonomics has always meant, by nature, a certain level of employee participation [29], for the last fifteen years approaches identified by the name of "participatory ergonomics" claim participation as a specific type of intervention producing its own impacts [13]. According to Imada [16] this approach requires that beneficiaries of an ergonomic intervention are involved in the development and implementation of the resulting solutions. Wilson and Haines [30] for their part insist on the notions of power and knowledge allowing employees to influence both processes and outcomes of their activities.

There are several reasons to use participatory ergonomics. Firstly it can generate or enhance ideas and design solutions, but it particularly allows an easier implementation of the changes. Moreover, participatory approaches will enhance the experience and expertise of people [9]. The results are thus more positive for both the organization and individuals $[30,13]$. Finally, participation appears as a central factor in the context of a risk prevention approach as it will have a significant impact on the safety climate and behaviors at work.

\subsubsection{Participation: a critical factor of prevention}

Participation is seen as a key factor in preventing accidents. Rightly, as Simard et al. [24] define it as "a powerful factor in effective prevention efforts". Thus, giving the opportunity or even encouraging operators to participate in the management of safety reduces accidents and their severity [21]. It also helps to increase compliance with the rules and safety procedures because, as shown by Geller [8], employees are more likely to accept and follow procedures they have helped to develop. Moreover, it seems that participatory approaches can take into account both factors of physical and psychosocial risks $[12,6]$ : they increase the sense of control employees feel over their work and positively change their self-image [25]. 
Many studies have shown that participation and involvement of employees in their own security was one of the main components of the safety climate $[7,5,22,11]$. As such, participation will therefore directly impact factors related to safety, including safety behaviors [23].

\section{A study of the impacts of safety climate and participation on safety behaviors}

\subsection{Background and scope of intervention}

The intervention related in this paper was conducted within a blast furnace plant. As part of its risk prevention program, the company decided to set up an action plan, in a participatory manner, by setting up working groups to solve health \& safety issues.

The involvement of the company in such a deliberate and dynamic safety improvement approach may be explained by several organizational factors. First, it contributes to the desire to develop a safety culture within the organization. The participatory approach is thus perceived as a way to involve employees in safety concerns in order to achieve the ambitious goals the company would like to reach in this area. Moreover, the company is determined to empower through that process the stakeholders in the organization and to change their behaviors, too often involved in the occurrence of workplace hazards.

The scope of intervention was limited to a specific area of the plant (actually one of the most hazardous, where the cast iron flows from the blast furnaces) and involved 230 employees in total. Among them, about 80 employees from all hierarchical levels and all functions have been actively involved in the participatory intervention by being incorporated into one of the twelve working groups established under the project. Each working group was composed of 6 to 8 members and co-facilitated by a "pilot" and an ergonomist.

The ergonomist played many roles as he initiates and guides the whole process but also acts as an expert, available for consultation by the working groups He was the referent person regarding the participatory process and tried to be as close as possible to the workers.

\subsection{The participatory framework}

The term "participatory ergonomics" actually includes a wide range of practices that do not have all the same implications and impacts for the organization [29].

Thus, it is necessary to describe in detail the type of participation established through an intervention in order to identify, within the scope of participation, what factors determine what impact [22]. It is possible to use the "Participatory Ergonomics Framework" developed by Haines et al. [22] to describe the type of participatory design on which an intervention is based. This classification describes participative processes according to 9 dimensions. Table 1 describes our intervention according to this framework.

The identification of the participatory dimensions involved in our participatory approach allows the interpretation of our results in a specific framework. The generalization of our results to another type of participatory intervention is therefore not guaranteed.

\section{Table 1}

Description of the type of participatory intervention using the « Participatory Ergonomics Framework » (Haines et al., 2002)

\begin{tabular}{|c|c|}
\hline DIMENSION & CATEGORIES \\
\hline Permanence of initiative & Temporary \\
\hline Involvement & Full direct participation \\
\hline Level of influence & $\begin{array}{l}\text { Entire organization - } \\
\text { Department - work group }\end{array}$ \\
\hline Decision-making power & Group consultation \\
\hline Mix of participants & $\begin{array}{l}\text { Operators - Line management - } \\
\text { Technical Staff - Union - Sup- } \\
\text { plier / purchaser }\end{array}$ \\
\hline Requirement to participate & Voluntary \\
\hline Topics addressed & $\begin{array}{l}\text { Physical design / specification } \\
\text { of equipment/workplaces/work } \\
\text { tasks }\end{array}$ \\
\hline Brief & $\begin{array}{l}\text { Problems identification - Solu- } \\
\text { tion development - Implemen- } \\
\text { tation of change - Set/up struc- } \\
\text { ture process }\end{array}$ \\
\hline Role of ergonomics specialist & $\begin{array}{l}\text { Initiates and guides process - } \\
\text { Acts as expert - Available for } \\
\text { consultation }\end{array}$ \\
\hline
\end{tabular}




\subsection{Research hypothesis}

This paper is focused on the measure of the impacts of participation, as a component of safety climate, on safety-related behaviors at work.

The following assumption is made: participation of employees will influence the perceived safety climate in a positive manner so as to generate a positive effect on safety-related behaviors.

\subsection{The measure of safety climate}

To assess the impact of our intervention on safety behaviors at work by taking into account both organizational and individual factors, a questionnaire survey was conducted four months after the starting date of the participatory ergonomics approach.

Population and sample. Our sample consists of 54 operators, all working in the department involved in the participatory process: 33 of them are taking part in a working group; the remaining 21 are not directly integrated in the participatory approach. The distinction between these two groups constitute the independent variable of effective participation in our study, complementary to those of personal perceived participation and general perceived participation, which are subscales of our perceived safety climate scale [23].

The average age of our sample is 37 years old. Regarding work contracts, $81.5 \%$ of the participants in our sample got a permanent employment contract whereas $18,5 \%$ got a fixed-term contract. Regarding length of service, $46 \%$ work in this department for less than 5 years and $54 \%$ for more than five years. 37 of them have experienced at least one workplace accidents.

Mode of questionnaire administration. Completion of the questionnaire was conducted by individual interviews with each operator, on the workplace. This mode of administration, even if it induces some bias, was chosen in order to read each question to the operator and ensure understanding. Even if we are fully aware of the possible effect of the mode of administration on the quality of the data collected, a selfcompletion mode was not envisaged in this specific industrial context because some workers actually have reading problems and would not have been able to participate in the survey.

Measurement scales. Following the structural model developed by Seo [23] (Figure 1), we measured perceived safety climate, perceived workload, perceived risk, perceived barriers and, finally, declared safety-related behaviors. However, because of space constraints, the present paper will only focus on the links between safety climate, employee participation in safety as part of the safety climate, and safety-related behaviors.

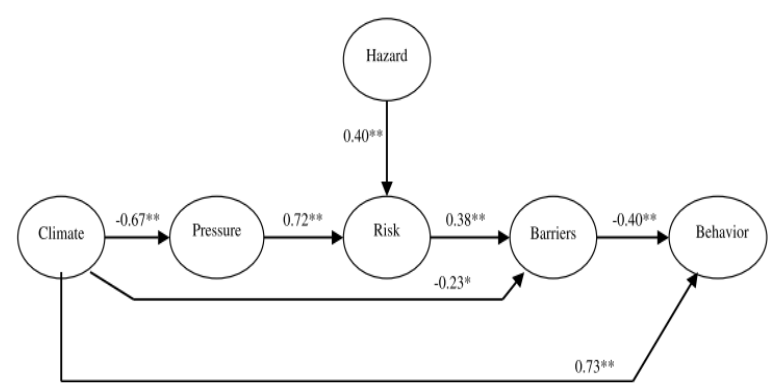

Figure 1: Structural model of unsafe work behavior (Seo, 2005)

Measurement scales used to assess the perceived safety climate are adapted from the Seo Safety Climate Scale (SSCS) [22], which is composed of $5 \mathrm{sub-}$ scales:

- management commitment (7 items)

- supervisor support (5 items)

- coworker support (6 items)

- general employee participation (7 items)

- personal perceived participation (7 items)

- competence level (6 items).

A subscale of personal participation, derived from the general employee participation subscale, has been added in order to distinguish the general perceived participation and the personal perceived participation. Moreover, note that the subscale of management commitment has not been administrated due to the opposition of the management.

The 10 items that constitute of our safety-related behaviors scale have also been created based on Seo's study [23]. Each item refers to a behavior that is typically involved in safety issues within the department. These behaviors have been identified on the basis of observations, accidents analyses and interviews of supervisors and managers. As an illustration, the behaviors targeted in this scale concern for example the wearing of safety equipment, the compliance to safety rules, workstation's tidiness or even the report of "near-accidents".

The questionnaire administrated to the workers that were involved in a working group also contains additional items regarding their evaluation on their implication in the participatory approach and the satisfaction they derive from it. 
Every scale of the questionnaire has been constructed as a Likert Scale, where items are formulated as statements. For each of them, participants are asked to indicate their level of agreement on a 8points scale from 1 (strongly disagree) to 8 (strongly agree). The higher the value, the more positive the perceived safety climate or the safer the behaviors. Reliability analyses were conducted among every scale or subscale to ensure that neither the translation of the scales in French, neither the adaptation of some items had impacted to global reliability of the scales and subscales (Cronbach's alpha $>.70$ in every case).

Sociodemographic variables observed are: age, length of service, employment contract, job position, work team, history of workplace accident.

\section{Results and discussion}

The results of this survey show first that the safety climate within the plant is generally perceived as positive by the employees. All subscales composing the safety climate scale collect a score above 5 of 8 and are all highly correlated $\left(\mathrm{p}<.01^{* *}\right)$. This good assessment of the global safety climate may come from the prevention efforts made within the company for years.

The results confirm the existence of a link between perceived safety climate and safety behavior $(r=.418$, $\mathrm{p}<.01 * *)$. The more the safety climate is seen as positive, the more the behaviors adopted appear to be safe. A safety climate perceived as positive would be potentially a factor favoring the development of safe work behaviors. However, among the dimensions of perceived safety climate, behaviors are only correlated with the personal participation $(\mathrm{r}=.580, \mathrm{p}$ $<.01 * *)$.

As a lever to change behaviors, it is interesting to try to understand the factors that will influence this safety climate. In this regard, the present study shows only a few links between perceived safety climate and socio-demographic variables such as age, length of service, employment contract or job position. It seems therefore that the factors that influence the perception of safety climate are more related to the organizational domain than to social or individual variables.

Age is fairly positively related to personal perceived participation $\left(\mathrm{r}=.249, \mathrm{p}<.05^{* *}\right)$ so that the older the worker, the higher the perceived participa- tion. Similarly, length of service is also related to that variable in the same direction $\left(\mathrm{t}(52)=-1.78 ; \mathrm{p}<.05^{* *}\right)$.

Regarding antecedents of workplace accidents, workers that did experience at least one accident perceive the general employee participation as lower $\left(\mathrm{t}(52)=1.84 ; \mathrm{p}<.05^{* *}\right)$ and are also less enthusiastic about safety competence level $\left(\mathrm{t}(52)=1.97 ; \mathrm{p}<.05^{* *}\right)$.

It is valuable to notice that it is the general employee participation that explains the main part of the variation among safety climate $(75 \%$ of variance explained) $(\mathrm{F}(1,52)=166.3, \mathrm{p}<.01 * *)$. In others words, it means that the company's perceived safety climate, whether positive or negative, is mainly determined by the positive or negative assessment of that specific aspect of daily participation of the employees to their own safety. Moreover, perceived personal participation is strongly related to effective participation in a working group in the context of our participatory intervention $(\mathrm{t}(52)=-2.44 ; \mathrm{p}<.02 *)$.

Regarding the contribution of our participatory intervention, the results show that effective participation is positively related to several key safety factors, and especially to safety-related behaviors. The workers that were actively involved in the participatory process show a higher score of safe behaviors than the ones that were not participating $(\mathrm{t}(52)=-1.97$; $\left.\mathrm{p}<.05^{* *}\right)$. Our main research assumption is therefore validated as it is now clear that participation impacts safety behaviors, directly but also indirectly through perceived safety climate.

Note also that the dynamic established during the intervention seems good since the average means for personal involvement in the participatory approach and satisfaction related to that participation are respectively equal to $5.78(\mathrm{~m}=5.78, \sigma=2)$ and 6.14 on $8(\mathrm{~m}=6.14, \sigma=1.34)$. However, beyond the simple act of participating in the process, it seems that the feeling of involvement the workers and the satisfaction they may derive from this participation are the most important factors. Thus, the more the employee feels effectively involved in the health and safety participatory process, the more his perception of personal participation to safety is strong $(\mathrm{r}=.59, \mathrm{p}$ $<.01 * *)$.

In terms of safety behaviors, there is a positive correlation between behaviors and age $(r=.268, p$ $<.05 *)$. The oldest employees thus reported having safer behaviors. Similarly, behaviors also depend on the length of service $(\mathrm{t}(52)=-2.44, \mathrm{p}<.05 *)$. They do not however link with job position, work team or history of workplace accidents.

Finally, note that the analysis of effective safety performance indicators shows no significant differ- 
ence, within the perimeter involved in the participatory process, in the frequency of workplace accidents between the period of the intervention and the same period a year ago. As we have explained above, this is not surprising not to see any immediate change on these indicators. First, since the participatory intervention only was in its beginnings, but also because the inferences from such indicators are only justified in the long term and on a large sample [9].

As a conclusion, our results confirm our initial assumption by showing the positive impact of participation on perceived safety climate and safety behaviors. The implementation of a participatory intervention appears to be an effective lever for change in behaviors. However, the fact that the effective involvement of employees in the process and the satisfaction they derive are determinants factors proves that the type of participatory intervention to set up is not trivial. It is not enough to involve people: one must also satisfied, through this approach, the multiple employees' expectations and achieve to involve them personally in the objectives of the intervention $[27,18]$. To give satisfaction to the operators involved, the management must therefore make resources available to achieve the solutions they propose. Otherwise, the benefits perceived at this early stage of the intervention may run out of steam quickly. To do this, some authors believe it is possible to control, before or during the implementation of the process, that some prerequisites ensuring the effectiveness of the latter are well present within the organization [30].

It would have been also interesting to repeat the measures by replicating the survey several months after the end of this one-year intervention. Indeed, the effect of a factor such as participation does not grow immediately, but requires the integration by employees of this new management type. In addition short term effects and long term effects are expected to differ and the results may therefore have shown some interesting links in the long term, especially by showing how the end of the participatory process could have impacted the perceptions of the safety climate and therefore probably the behaviors also.

\section{Conclusion}

After four months of intervention, the survey conducted among employees in order to assess the impacts of a participatory intervention on safety climate shows promising results. The benefits are numerous: a safety climate perceived as more positive but also safer attitudes and behaviors.

An important issue to emphasize is that, more than just participation; it is rather the involvement of employees in the participatory process and the satisfaction they derive from it that provide these benefits. The implementation of a participatory approach does not guarantee by itself the desired results. It must definitely be established so as to involve people. The type of participatory intervention implemented, taking into account many elements of the context, will therefore be a key factor in success or failure [18] and will have to be at the heart of the concerns of practitioners in the field of health and safety at work.

\section{Acknowledgements}

A part of the original work related in this paper was performed in the context of a Master's thesis realized at the University Paul Verlaine of Metz (France).

\section{References}

[1] Brown, K.A., Willis, P.G., Prussia, G.E. (2000). Predicting employee behavior in the steel industry: development and test of a sociotechnical model, Journal of Operations Management, $18,445-465$.

[2] Choudry, R.M., Fang, D., \& Mohamed, S. (2007). The nature of safety culture: A survey of the state-of-the-art, Safety Science, 45, 993-1012.

[3] Cox, S., \& Cox, T. (1991). The structure of employee attitudes to safety: a European example, Work and Stress, 5, 2, 93-106.

[4] Coyle, I.R., Sleeman, S.D., \& Adams, N. (1995). Safety climate. Journal of Safety Research, 26, 4, 247-254.

[5] DeJoy, D.M., Schaffer, B.S., Wilson, M.G., Vandenberg, R.J., \& Butts, M.M. (2004). Creating safer workplaces: Assessing the determinants and role of safety climate. Journal of Safety Research, 35, 81-90.

[6] Eklöf, M., Ingelgård, A., \& Hagberg, M. (2004). Is participative ergonomics associated with better working environment and health? A study among Swedish white- collar VDU users International Journal of Industrial Ergonomics, 34, 355-366

[7] Flin, R., Mearns, K., O’Connor, P., \& Bryden, R. (2000). Measuring safety climate: identifying the common features, Safety Science, 34, 1-3, 177-192.

[8] Geller, E.S. (2001). The Psychology of Safety Handbook. Florida: CRC Press.

[9] Glendon, A.I., Clarke, S.G., McKenna, E.F. (2006). Human safety and risk management. Florida: CRC Press.

[10]Glendon, A.I., \& McKenna, E.F. (1995). Human safety and risk management. London: Chapman and Hall

[11]Hahn, S.E., \& Murphy, L.R. (2008). A short scale for measuring safety climate. Safety Science, 46, 1047-1066

[12]Haims, M.C., \& Carayon, P. (1998). Theory and practice for the implementation of "in house" continuous improvement 
participatory ergonomics programs, Applied Ergonomics, 29 $6,461-472$.

[13]Haines, H., Wilson, J. R., Vink, P., Koningsveld, E. (2002). Validating a framework for participatory ergonomics. Ergonomics, 45, 4, 309-327.

[14]Health and Safety Commission (1993). Third report: organizing for safety. ACSNI Study Group on Human Factors. London: Her Majesty's Stationery Office.

[15] Heinrich, H.W. (1931). Industrial Accident Prevention, NewYork : McGraw-Hill.

[16] Imada, A.S. (1991). The rationale and tools of participatory ergonomics. In K. Noro \& A.S., Imada (Eds) Participatory Ergonomics (pp. 30-51). London: Taylor and Francis.

[17]Lutness, J. (1987). Measuring up: assessing safety with climate surveys, Occupational Health and Safety, 56, 20-26.

[18] Matthews, R.A., Gallus, J.A., \& Henning R.A. (2011). Participatory ergonomics: Development of an employee assessment questionnaire. Accident Analysis and Prevention, 43, 360-369.

[19]Mearns, K., Whitaker, S.M., \& Flin, R. (2003). Safety climate, safety management practice and safety performance in offshore environments, Safety Science, 41, 641-680.

[20] Morrow, P.C. \& Crum, M.R. (1998). The effects of perceived and objective safety risk on employee outcomes. Journal of Vocational Behavior, 53, 300-313.

[21] O'Toole, M.F. (1999). Successful safety committees: participation not legislation. Journal of Safety Research, 30, 1, pp. 39-65.

[22] Seo, D.-C., Torabi, M.R., Blair, E.H., Ellis, N.T. (2004). A cross-validation of safety climate scale using confirmatory factor analytic approach. Journal of Safety Research, 35, 4, 427-445.
[23] Seo, D.-C. (2005). An explicative model of unsafe work behavior. Safety Science, 43, 187-211.

[24] Simard, M., Carpentier-Roy, M.C., Marchand, A., Ouellet, F. (1999). Processus organisationnels et psycho-sociaux favorisant la participation des travailleurs en santé et en sécurité du travail. Québec : IRSST.

[25] St-Vincent, M., Toulouse, G., \& Bellemare, M. (2000). Démarches d'ergonomie participative pour réduire les risques de troubles musculo-squelettiques : bilan et réflexions, Perspectives Interdisciplinaires Sur le Travail Et la Santé, 2, 1.

[26] Varon, U., \& Mattila, M. (2000). The safety climate and its relationship to safety practices, safety of the work environment and occupational accidents in eight wood processing plants. Accident Analysis and Prevention, 32, 761-769.

[27] Vink, P., Imada, A.S., \& Zink, K.J. (2008). Defining stakeholder involvement in participatory design processes, Applied Ergonomics, 39, 519-526.

[28] Williamson, A.M., Feyer, A.-M. (1990). Behavioral epidemiology as a tool for accident research, Journal of Occupational Accidents, 12, 207-222

[29] Wilson, J.R. (1991) Participation - a framework and a foundation for ergonomics? Journal of Occupational Psychology, 64, 67-80.

[30] Wilson, J. R., \& Haines, H. M. (1997). Participatory ergonomics. In G. Salvendy (Ed.), Handbook of Human Factors and Ergonomics (pp. 490-513). NY: Wiley.

[31]Zohar, D. (1980). Safety climate in industrial organizations: theoretical and applied implications, Journal of Applied Psychology, 65, 1, 96-101.

[32]Zohar, D., \& Luria, G. (2005). A multilevel model of safety climate: cross-level relationships between organization and group-level climates, Journal of Applied Psychology, 90, 4, 616-628 